\title{
Editorial, Volume 10 (2019)
}

On behalf of the Editorial Board, it is with great pride and sincere privilege that I am writing this message to present the volume 10 (2019) of the JOURNAL OF ADVANCES IN LINGUISTICS The issue comes from a long process, and we took all the necessary steps to make it a high-caliber scientific publication. We are relying on the collaboration of all our Editors, reviewers, and contributors to make it a contemporary, lively, and relevant publication.

This issue features 10 scientific papers from various subjects in the scope of the journal. It is clear from this collection of articles that the research in this particular area is flourishing. It is hoped that this article will motivate researchers to contribute to the future advancement of this interesting research area.

JAL has adopted new policies in 2019.

Peer Review Policy: Journal uses a blind peer review system to ensure originality, timeliness, relevance, and readability.

Open Access Statement: All articles published in JAL are fully open access, immediately freely available to read, download, and share.

Plagiarism Policy: JAL will check plagiarism for all the articles before prior publication.

Digital Archiving Policy JAL has electronic backup and preservation of access to the content of its journals via PKP Preservation Network (PKP PN).

Licencing Policy: All articles published in this journal are licensed under a Creative Commons Attribution 4.0 International License.

We welcome new Editorial Board members who began their terms in 2019, and We thank Editorial Board members who rotated off the Board in 2019.

As an Editorial team, our goal for 2020 is to build on the good foundation laid in 2019, improve the reputation of the journal and improve its indexing databases, citation, and impact factor. In this regard, we welcome articles/papers that cover wide-ranging topics in Linguistics.

We are also committed to making speedy editorial decisions. Quality reviewer reports first editorial decisions within 6-8 weeks, and second (and final) editorial decisions within 4 weeks' of receiving revised papers are all part of our vision for taking the journal forward.

We promise to improve and promote our role in this partnership and therefore look forward to your valued contributions to the journal in 2020.

Finally, I would like to take this opportunity to show gratitude to all of the authors, referees, and Editorial Board members for their immense efforts and contributions in making this issue valuable reading for all who are fascinated by the recent advancements in the various arena of chemistry. I anticipate that the readers will definitely enjoy the contributors' work published in this issue as much as we have. Finally, I wish you a happy and wonderful 2020.

\section{Chief Editor}

\section{Dr. Ghayth Al-Shaibani}

Assistant Professor of Applied Linguistics/Critical Discourse Analysis, English Language and Communication Department, Faculty of Social Sciences and Liberal Arts, UCSI University, Cheras, Kuala Lumpur, Malaysia Formerly Honorary Lecturer and Senior Lecturer at Universiti Sains Malaysia, Malaysia 